\title{
Essence and the Grounding Problem
}

MARK JAGO In Reality Making, ed. M. Jago, Oxford University Press, 20I6, pp. 99-г 20.

Abstract: Pluralists about coincident entities say that distinct entities may be spatially coincident throughout their entire existence. The most pressing issue they face is the grounding problem. They say that coincident entities may differ in their persistence conditions and in the sortals they fall under. But how can they differ in these ways, given that they share all their microphysical properties? What grounds those differences, if not their microphysical properties? Do those differences depend only on the way we conceptualise those objects? Are they primitive facts about reality? Neither option is pleasant for the pluralist, but what else can she say? To respond to the grounding problem, the pluralist should first tell a story about what material objects are. If that story explains how the modal and sortal properties of objects are grounded, in a way that allows for differences between coincident objects, then she has a response to the problem. That is precisely my aim in this paper.

Keywords: Essence, grounding, material objects, modality, bundle theory

\section{Introduction}

$\mathrm{W}$

ATCHING ANNA KNIT, it's clear that the scarf she's making and the yarn she's making it from are different things. After all, when she bought the yarn, no scarf existed; and she knits the yarn to create the scarf, not vice versa. Most metaphysicians agree. But suppose she later knits another scarf, from another length of yarn, and joins the two halves together. That scarf has two halves, neither of which are identical to the lengths of yarn from which they were knitted. The whole scarf is distinct from the combined length of yarn from which it is made. But the combined yarn came into existence precisely when the whole scarf did; and, let's suppose, both will cease to exist simultaneously in a terrible disaster. So we have distinct objects which nevertheless spatially coincide throughout their entire existence: the scarf, and the combined length of yarn. If you agree with me on this, you're a pluralist about coincident objects. If not, you're a monist about coincident objects.

Pluralists can argue for their position by considering the de re modal properties of the objects in question. The combined scarf - call it Chunky - would not survive being unravelled, whereas the combined length of yarn - call it Woolly - would. Chunky and Woolly differ in their properties and so must be distinct entities. Whether one accepts this argument for pluralism (as I do) depends on one's account of modal predication. One might treat modal predicates like 'could survive being unravelled' as Abelardian predicates (Noonan I99I), which switch their reference when attached to different subject-position terms. This makes the inference from ' $F a$ ' and ' $a=b$ ' to ' $F b$ ' invalid when ' $F$ ' is an Abelardian predicate. 
Counterpart theorists often accept this view and, as a result, reject the argument from de re modality for pluralism.

As I indicated above, I find pluralism to be well-motivated, independently of the modal argument; and I've argued for pluralism (by arguing against monism) elsewhere (Barker and Jago 20I4). My aim in this paper is not to argue for pluralism, but to defend it against its most serious problem. Chunky and Woolly share all their microphysical parts. Any atom, sub-atomic particle, superstring or whatever that contributes to the physical make-up of Chunky thereby contributes to the physical make-up of Woolly, and vice versa. Yet Woolly can survive in situations (such as total unravelling) which would destroy Chunky, and Chunky can survive in situations (such as bit-by-bit replacement of parts) which would destroy Woolly. This fact appears miraculous! What makes it the case that Chunky and Woolly have these differing persistence conditions, if not their microphysical parts?

This is the grounding problem for pluralists about coincident objects. It is the most serious problem for pluralists about coincident objects. If modal differences (including differences in persistence conditions) between coincident objects cannot be grounded, then pluralism about coincident objects looks to be in bad shape. How should the pluralist respond? Her options seem to be limited from the start. Some have suggested that modal differences between coincident objects depend on the way we conceptualise the objects in question $\left(\mathbb{S}_{3}\right)$. Others have claimed that the pluralist must take such modal differences to be primitive facts about our world $\left(\$_{4}\right)$. Both approaches are unappealing; and the pluralist can do much better.

My aim in this paper is to set out (what I take to be) the best response to the grounding problem. The response requires us to adopt a particular view of what material objects are. But that should come as no surprise. To understand how Chunky and Woolly are two and not one, and to understand how their differences are grounded, we first need to understand what Chunky and Woolly are.

The rest of the paper is as follows. I set out the grounding problem in more detail in $\mathbb{2}_{2}$. In $\mathbb{S}_{3}$, I argue that we should not locate the relevant differences between coincident objects in facts about our concepts. In $\$_{4} \mathrm{I}$ argue that we should not take those differences to be primitive. In $\mathbb{5}_{5}$, I assess Kris McDaniel's (200I) and L. A. Paul's (2002; 2006) claim that a suitable bundle theory of objects avoids the problem. Their approaches indeed make progress, but fall short of being a full solution. I present and defend my approach in $\$ 6$.

\section{The Grounding Problem}

Of the many objections that have been aimed at the pluralist, all but one are relatively easy to shake off. The pluralist is accused of double-counting; of having double-vision; of having an excessively profligate ontology; of being unable to account for the identities of co-located material objects. (See, for example, Lewis I986; Robinson I985; and Zimmerman 1995.) She may reply that larger ontologies often out-perform smaller ones on key issues (and argue that hers is 
one of these cases), and hence that both her vision and basic arithmetic are fine, thanks for asking.

The problem to which she cannot respond so easily is to explain how coincident objects can ever differ in any respect, given that they do not differ in certain other key respects. Chunky and Woolly are qualitatively indistinguishable in all microphysical respects and yet they differ in their persistence conditions and the sortals under which they fall. Chunky is a scarf, whereas Woolly, a mere mass of wool, is not. Woolly can survive being completely unravelled, whereas Chunky cannot. How can these differences be explained? They 'seem to stand in need of explanation and yet there seems to be no further difference between [Chunky and Woolly] that is poised to explain, or ground, these differences' (Korman 20I I, $\left.\mathbb{}{ }_{3} \cdot \mathrm{I}\right)$. For, according to the pluralist,

there are two objects exactly alike in every empirically discriminable intrinsic respect, one of which has the stamina to withstand pressures and survive changes that the other cannot. Should not two physical objects constructed in precisely the same way out of qualitatively identical parts have the same capacities for survival under similar conditions? (Zimmerman I995, 87)

This is the grounding problem, as raised in various ways by Burke (I992), Heller (1990) and Zimmerman (I995).

The general form of the problem is: how can Chunky and Woolly differ in various ways, given that they are qualitatively identical in other ways? The ways in question are often taken to be modal and microphysical, respectively: then, the problem is to explain modal differences, given a lack of microphysical differences. But the problem is not solely about how modal properties are grounded, for there are other ways in which Chunky and Wooly differ. They differ in what they are; they have different identities and natures; they have different essential properties and fall under different sortals. We may but need not treat these differences as modal differences; indeed, we may want to use these features to explain the modal differences. Chunky and Woolly survive in different situations because they have different natures, or different essences. But then, how are we to ground this difference in their nature? Chunky and Woolly also differ in some of their relational features. When I admire Anna's handiwork, it is Chunky (and not Woolly) I admire. I might desire to own Chunky, without having any particular attitude towards Woolly. And were Anna to misplace her handiwork, it would be Chunky, not Woolly, that she would miss. One could run a grounding objection using any of these differences between Chunky and Woolly. But let's focus here on differences in modal and sortal properties.

The grounding problem is clearly worrying for anyone who's tempted to think that all of an object's properties depend on its microphysical properties. Chunky and Woolly differ in their properties, but not in their microphysical properties, and so some of their properties (including their modal properties) cannot be explained purely in terms of their microphysical properties. For that reason, the grounding problem is equally worrying for anyone who wants to give an explanation of modal properties in terms of non-modal properties. A modal property, such as 
being capable of being radically reshaped without being destroyed, seems to stand in need of explanation. Why is it that the wool, but not the scarf, has this property?

One explanation might appeal to the sortals under which an object falls. Chunky has certain modal properties because it's a scarf; Woolly lacks those modal properties because it's a mass of wool, not a scarf. Many feel that the explanation can't end there, however. Isn't there something to say about why this entity, but not this co-located, microphysically indistinguishable one, is a scarf? It's natural to think that something counts as a scarf because it satisfies certain criteria. But then, why doesn't the co-located, microphysically indistinguishable mass of wool satisfy those criteria? Perhaps it's because the criteria includes certain modal properties. But then, we can't appeal to sortal possession to explain those modal properties.

An alternative explanation might start from facts about identity: Chunky is identical to Chunky, whereas Woolly is not identical to Chunky. Whilst those identity facts are a clear difference between the two entities, it is hard to see how those bare facts alone could provide a satisfying explanation of their modal differences. Why is it that being identical to Chunky gives rise to certain persistence conditions, whereas being identical to Woolly gives rise to different persistence conditions? (That is not to say that the strategy is hopeless. If we knew more about what it is to be Chunky, or what it is to be Woolly, then an explanation might be forthcoming: see $\$ \$ 6-7$.)

One might think that there's an easy way out of the problem, by reasoning as follows. First (the reasoning goes), the problem is about the failure of supervenience of modal and sortal properties on microphysical properties. And second, there are alternative notions of supervenience according to which the modal and sortal properties of coincident objects do supervene on their microphysical properties. Zimmerman (I995) sketches one such notion:

one may insist that sortal properties do supervene upon the intrinsic physical properties of things, but that an object possessing intrinsic properties sufficient to ensure that something falls under the supervening sort may not itself be of that sort; its having these grounding properties merely guarantees that there is something coincident that is of this sort. (Zimmerman I995, 88)

The notion he has in mind (call it supervenience* ${ }^{*}$ is as follows:

SuPERVENIENCE* Property $F$ locally supervenes* on properties $F_{1}, \ldots, F_{n}$ iff, necessarily, for any entity that possesses $F_{1}, \ldots, F_{n}$, there is a coincident entity which possesses $F$.

This notion allows distinct sortal properties, persistence conditions and so on to supervene* locally on a common set of microphysical properties. So, one might think (along with Zimmerman) that our initial problem of grounding sortal differences has been solved.

On reflection, however, it is clear that this move does nothing to help with the original problem. The task was to identify what, if anything, grounds the differences between coincident objects. We want a metaphysical explanation of 
how those differences arise. Supervenience ${ }^{*}$ merely allows us to say that such differences supervene ${ }^{*}$ on the microphysical. As a consequence, we can't get the kind of explanation we want from SUPERVENIENCE* ${ }^{*}$ (The same goes for other revised notions of supervenience which are compatible with coincident objects; Bennett (2004a) makes the case in detail.) The problem remains.

\section{Conceptualist Solutions}

In this section, I discuss conceptualist responses to the grounding problem, on which 'the distribution of sortalish properties across the world is the result of human attitudes, concepts, and conventions' (Bennett 2004b, 345). This approach is a form of anti-realism about material objects: the claim is that our concepts, and the way we exercise them, is what gives material objects the sortals they have. Absent that conceptual activity, things do not have sortal properties or persistence conditions. But that is just to say that, absent conceptual activity, we shouldn't speak of things at all; rather, there is only stuff or matter distributed in a certain way. As Dana Goswick has it:

We are not, as the standard Realist claims, in the business of trying to ascertain the essential natures of independently existing objects. Rather, we are in the business of creating-given certain distributions of matter in space-timeobjects whose essential natures match our concepts. (Goswick 2010, 443)

Mark Johnson agrees with this anti-realist line, describing as 'bogus' the idea that

the difference between an $F$ and its constituting matter must be a deep metaphysical difference secured by an extra ingredient of the $F$. (Johnston I992, IO3)

Instead,

The crucial distinction [between an $F$ and its constituting matter] is a consequence of representing the world as a world of both objects and pieces of matter surviving material change, but surviving different kinds and degrees of material change. (Johnston I992, I04)

The key idea here is that it is our representations, and nothing more, that make it the case that the $F$ and its constituting matter are two, not one.

All pluralists will agree that, whenever we have a region $r$ in which certain microphysical properties are present, there will exist in $r$ distinct entities $x$ and $y$ possessing distinct sortals $S_{1}$ and $S_{2}$, respectively. Given the microphysical properties present in the scarf-shaped timeslice over there, for example, we find both Chunky, a scarf, and Woolly, the mass of wool which materially constitutes it. If any region contained those microphysical properties we'd find both a scarf and a distinct mass of wool there (in our world, at least). Call such statements pluralist conditionals. What is distinctive to the conceptualist claim is that it is our concepts which make pluralist conditionals true. 
Bennett $\left(2004 \mathrm{~b}, \mathbb{S}_{3}\right)$ argues against conceptualism on two grounds. Her first argument goes as follows. The antecedents of pluralist conditionals specify that such-and-such microphysical (or, more generally, 'non-sortalish') properties be present in the region in question. But to evaluate such antecedents, one cannot appeal to sortal-possessing entities as the possessors of those properties. That would be to assume the very kind of realist position which conceptualists want to deny. So to make sense of such antecedents, conceptualists will have to say either that there are entities lacking any sortal properties, or else that, prior to our conceptual activity, microphysical (or other 'non-sortalish') properties may be present in a region without being possessed by any entity whatsoever. Bennett $(2004 \mathrm{~b}, 50)$ thinks that neither option is attractive.

I agree with Bennett that the former is not an option for the conceptualist. Conceptualists argue that we bring particular entities into being precisely by conceptualising them in some way or other. But to conceptualise an object in the way required is precisely to think of it under some sortal or other. Hence, by conceptualist lights, there can be no material objects wholly lacking in sortal properties. However, Bennett's second option remains open to conceptualists. On this option, prior to our conceptualisations, microphysical properties may be present in a region without being possessed by any material object. As Goswick says, our conceptual activity creates material objects with sortal properties, but only against the background of 'certain distributions of matter in space-time' (Goswick 20I0, 443), which are independent of our conceptualisations. So this option strikes me as being precisely what a conceptualist should say.

The idea that properties may be present in some region in a way metaphysically prior to the existence of material objects is plausible on independent grounds. Bundle theories of material objects view properties as being metaphysically prior to material objects. Those theories may take material objects to be bundles of tropes, or particular instances of universals (rather than the universals themselves). I find such theories highly plausible, not least because they can be made to cohere well with contemporary physics on what they take to be ontologically fundamental: spacetime and properties, but not material objects. Indeed, I will present a (nonconceptualist) theory along these lines in $\$ 6$ as a solution to the grounding problem. Given that this option is plausible, Bennett's first argument against conceptualism is not effective.

Bennett's second argument (2004 b, 350-I) against conceptualism is that, for conceptualism to be viable, pluralist conditionals would need to be conceptual truths. But, she says, they are not conceptual truths:

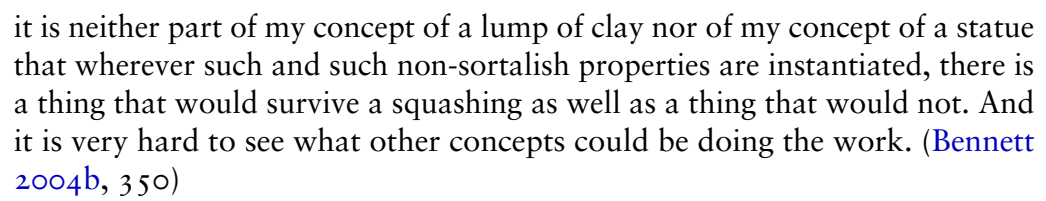

Bennett is surely right here: pluralist conditionals are not conceptual truths. But why does she claim that those conditionals must be conceptual truths for conceptualism to be viable? The conceptualist must claim that it is our concepts 
that make the conditionals true; she need not claim that they are conceptual truths (in the way that 'all red things are coloured' is a conceptual truth). A truth can be grounded in our concepts without thereby being a conceptual truth: 'there exist concepts' and 'there is conceptual activity going on now' are two such truths. The conceptualist should claim, in the same way, that pluralist conditionals are conceptually grounded, but not conceptual truths. If this is indeed an option, then Bennett's second argument against conceptualism fails as well.

It is not my intention to defend conceptualism, however. The real problem with the conceptualist proposal is this. It is part of the conceptualist story that, for an entity of kind $K$ to exist, something must possess and exercise a concept of entities of kind $K$. Whatever it is that possesses that concept, it must (trivially!) be the kind of entity capable of having and exercising concepts: call it a concept possessor for short. But for this kind of entity to exist, there must (by conceptualist lights) be exercised a corresponding concept, the concept of concept possessor. So, according to conceptualism, there can be no material objects unless something has and exercises the concept concept possessor. This view rejects the possibility of there existing only very simple concepts: concepts like predator, prey and potential mate, for example. This seems like a very genuine possibility; indeed, it is highly plausible that, at some point in our evolutionary past, those were the only concepts being exercised. It was only later that we came to exercise more advanced concepts (such as the concept concept possessor). The conceptualist's version of our evolutionary history must be radically different from this. On their version, there was nothing but matter-possessing-properties for most of the world's history; and then, suddenly, advanced concepts and the corresponding entities simultaneously emerge into being. I find that version of events hopelessly implausible.

Why is this objection not just the familiar complaint against conceptualism, which maintains that there could have existed entities in the absence of any concepts? The latter objection flatly rejects the conceptualist's central claim, that it is conceptualisation that brings entities into existence by providing form to the otherwise formless matter-possessing-properties. This objection begs the question against the conceptualist. But the objection I ran above is not like this. It grants the conceptualist's central premise. The objection is not that conceptualism denies possibilities in which there are objects but no corresponding concepts. Rather, the objection is that conceptualism leaves no room for the existence of simple concepts (such as the concepts predator, prey and potential mate) in the absence of advanced concepts (such as the concept concept possessor). That's why I reject conceptualist accounts.

\section{Primitivist Solutions}

When the question was first posed, 'what kind of fact grounds the differences between collocated material objects?', the only options seemed to be these: (i) microphysical facts; or (ii) facts about us and our concepts. If both of these options fail, as I (and many others) think they do, then the pluralist seems to be 'backed 
into a corner', having to admit that the interesting differences between coincident objects 'are not in fact grounded in anything at all' (Bennett 2004 b, 352). This is the primitivist response to the grounding problem (Bennett 2004b), although (as Bennett allows) it might be more apt to call it a dismissal of the problem.

Adopting the primitivist option, in this case and in many others, is a huge theoretical cost. Just how big such costs are, and how they should be weighed against the costs of competing theories, is always hard to settle. Most would accept that anyone tempted by primitivism has at least to explain how the facts about the phenomenon in question could be primitive. One cannot simply say, 'it's primitive!' and leave it at that.

Bennett (2004b) thinks that the primitivist response to the grounding problem is the pluralist's only option. Pluralism stands or falls with primitivism about the possession of sortals and related properties. On her picture, the pluralist must say the following: whenever there is a spatiotemporal region with fundamental properties instantiated as they are in Chunky's region, then there exists in that region both a mass of wool and a numerically distinct scarf, which nevertheless share all their microphysical characteristics. They differ in their sortal properties, and consequently in their persistence conditions and in other aspects of their modal profiles. But there is no further explanation of why they differ in these ways. One cannot reduce the fact that Chunky but not Woolly is a scarf, and hence that Chunky could not survive unravelling (whereas Woolly could), to any further fact.

The best a pluralist can do, according to Bennett, is to explain why there exist distinct but coincident objects possessing different sortals in that region. Her explanation goes like this $(2004 \mathrm{~b}, 344-5)$. Any possible modal profile one can come up with, based on the microphysical (and, more generally, the non-sortalrelated) properties $F_{1}, \ldots, F_{n}$ instantiated in region $r$, is itself instantiated in region $r$. Call this the modal plenitude principle. Since (for the pluralist) differences in modal profile reflect differences in identity, each of those modal profiles is instantiated by a numerically distinct object in region $r$. For present purposes, a 'modal profile' built from $F_{1}, \ldots, F_{n}$ specifies whether each $F_{i}$ is necessary to the object in question. So this picture is this: for any consistent way of assigning 'is necessary' or 'is contingent' to the non-sortal-related properties in a region, there's an object in that region with precisely that modal profile.

On this proposal, it isn't a primitive fact that there are many coincident entities in a given region. This fact is explained by the plenitude of available modal profiles, plus the stipulated fact that all such profiles are instantiated. What is primitive is which entity has which modal profile. If object $x$ has modal profile $M$, then distinct but coincident object $y$ does not; and it's a primitive fact that $x$ and not $y$ has M. It's primitive that Chunky but not Woolly is a scarf. The point of Bennett's proposal is not to explain away primitive facts, but rather to justify their existence. (I should stress that Bennett does not commit to this view. She thinks the pluralist has no better option, but is not herself a pluralist.)

Let me briefly mention a worry for this approach. For it to offer some justification for primitivism, the modal plenitude principle must predict that, for any of the relevant differences we find between coincident objects, there will exist coincident objects differing in those ways. The worry is that not all of the 
differences we find between coincident objects are (directly) modal differences. As noted above, it can be that Chunky (but not Woolly) is admired, desired or missed. And as Fine (2003) argues, a statue may be valuable and aesthetically pleasing, whereas its constituting matter in itself is neither. For Bennett's justification for primitivism view to fly, therefore, it must be that all of these differences reduce to, or can be explained in terms of, their modal differences.

There is at least one difference between Chunky and Woolly which cannot be reduced to their modal differences, however. Chunky and Woolly differ in their essences: Chunky is essentially a scarf, and so is essentially wearable, essentially of scarf-like shape and so on, whereas Woolly is not. (Woolly is wearable and of scarf-like shape, but not essentially so.) These essential properties cannot be reduced to their de re modal properties. It is de re necessary of any entity that, if it exists, then $1+1=2$; but this is not part of any material entity's essence (Fine I994, 4-5). Fine's point is a powerful one. In the present context, it severely damages Bennett's defence of primitivism. Some differences between coincident entities remain unaccountable, even if one accepts the modal plentitude principle.

Although this problem is serious, it is not my primary source of dissatisfaction with Bennett's primitivism. Bennett's modal plenitude principle is very plausible: the pluralist should not say that the Chunky-shaped region is inhabited only by Chunky and Woolly. She must also admit the existence of a great number of extraordinary entities, coincident with Chunky and Woolly, but differing in their modal properties. But why are there so many coincident entities? Saying 'because the plenitude principle is true' is not very satisfying: why is it true? For Bennett, it's truth is merely a stipulation, designed to make primitivist pluralism less unappealing. But, in positing an ontology which vastly outruns our conceptual schemes, the plenitude principle can receive no support from intuition and little from theoretical ideology. In short, it isn't the kind of principle which one should merely stipulate. Rather, one needs an account of what objects are which will entail that any material object is coincident with many others. But once one has such an account, it is not so clear that a pluralist must accept the primitivist line after all.

That is the line I will take in the remainder of the paper. A pluralist should respond to the grounding problem by first giving an account of what material objects are which predicts - or better still, explains - the existence of coincident objects differing in such-and-such ways. In the next section, I'll examine one such approach; I offer my own in $\$ 6$.

\section{Bundle Theory to the Rescue?}

The first theory of material objects I will discuss is a bundle theory of material objects, which I take from McDaniel (200I) and Paul (2002; 2006). This option offers a response to the grounding problem which has some points of similarity with Bennett's primitivism but which, in crucial ways, outperforms it. On McDaniel's and Paul's theories, material objects are property-bundles, where those bundles are understood as mereological sums of properties: they are wholes, 
with properties as parts. (Those properties are tropes, on McDaniel's story, and 'logical parts' on Paul's.) Both McDaniel and Paul argue that this mereological bundle theory gives the pluralist a plausible response to the grounding problem. I'll argue that the response is indeed an improvement on Bennett's primitivism, but that it falls short of an adequate solution.

According to mereological bundle theory, a material object has properties as parts (with 'part' understood mereologically). On this view, the spatiotemporal property being in Cambridge in August, 2013 is a part of me. A material object's parts will include modal, sortal and other 'sortalish' properties, in addition to its spatiotemporal and microphysical properties. Any pluralist accepts that properties in the last two categories do not determine sortalish properties. So it may be that there are material objects (qua mereological sums of properties) $a$ and $b$ which overlap precisely on their spatiotemporal and microphysical parts, but differ on their sortalish parts. This is just what the pluralist wants to say.

On this account, the modal differences between Chunky and Woolly are primitive differences, in that they cannot be explained by or grounded in other features of Chunky or Woolly. But now we have an explanation of that primitive difference: they differ in such-and-such ways because they are different objects. They are different sums of properties, and so they must differ, primitively, in at least some of their properties. This is a basic truth about any two mereological sums; it isn't some feature that has been hand-written in to the theory of objects. We might even say that, although the relevant modal differences are not grounded in some other class of properties, they are nevertheless grounded in the identities of the objects in question. The very identities of Chunky and Woolly, qua sums of properties, are what ground their modal (and other) differences.

This is surely an improvement on Bennett's primitivism. Nevertheless, the approach faces problems. To see the first problem it faces, note that the bundle theorist should not claim that bundle-membership is primitive for all bundled properties. An object that has being coloured as a part will do so because it has some other property, perhaps being green, as a part. The part being green grounds the part being coloured. Some of the bundled properties are derivative upon others in the bundle: the former are in the bundle because the latter are in it. Call the latter properties primitive parts of the bundle. (Alternatively, it may be that bundles contain only sparse properties: mass, charge, spin and spatiotemporal properties, for example. This is McDaniel's (200I, 27I) preferred option. Then, whether or not $x$ is $F$ will depend on which sparse properties are parts of $x$. In this case, all parts of $x$ are primitive parts.)

What is the status of modal properties within a bundle: are they primitive or derivative parts? Let's consider what McDaniel and Paul say on the matter. For McDaniel, tropes are sparse and 'the job of determining what tropes there are is best occupied by empirical scientists' (200I, 27I). The primitive part of a bundle will be microphysical properties and relations; modal and sortal properties will be derivative features of material objects. But, given that coincident bundles share all their microphysical properties (and relations), it seems that McDaniel's approach cannot account for modal differences between coincident entities.

Paul (2006, 640-48) develops an alternative approach, based on a standard 
reductive story about modal properties. On this story, de re modal properties are given in terms of counterpart relations, which in turn are analysed in terms of similarities between objects. On this story, a bundle's modal properties are ultimately a matter of which bundles it resembles, in certain respects. Paul's twist on this idea is that coincident bundles share a spatiotemporal 'core' but differ in resemblance-properties. The Woolly-bundle includes the monadic property of resembling an unravelled mass of wool, whereas the Chunky-bundle does not. It is these differences in resemblance-properties between the two bundles that determines their modal differences.

This view does not appeal to primitive modal differences between Chunky and Woolly. But it does appeal to primitive differences in what they resemble. This feature of the view is hard to swallow: resemblance (in any respect) between two bundles of properties does not seem to be a primitive matter. If two bundles (resemblance-properties aside) are completely disjoint, with no properties in common, then they do not resemble one another in any respect; whereas two bundles which overlap to a very great extent will resemble one another in many respects. In general, given any two bundles (not including resemblance properties or relations), the facts about resemblances between them are thereby fixed. So we should not take resemblance properties to be primitive parts of bundles. But if we cannot, then Paul's suggestion fails.

(Paul also suggests two non-reductive accounts of modal differences between coincident objects: one 'primitivist', one 'emergentist'. The former is very similar to Bennett's primitivism $\left(\mathbb{S}_{4}\right)$. On the latter, coincident bundles which have $F$ as a part may differ in that just one of them has being accidentally $F$ as a part. In that case, being accidentally $F$ is not grounded in the overlapping parts of the two bundles, and hence is a primitive part of one of those bundles. So this view reduces to the view that (at least some) modal properties are primitive parts of bundles and hence this view, too, is a primitivist account of modal differences.)

An alternative approach for the bundle theorist is to claim that sortal properties are primitive parts of bundles. When there is matter arranged in a way suitable for woolly scarfs, there exist two bundles: one containing the sortal being a scarf, and another lacking that sortal. The presence or absence of being a scarf in those bundles is primitive. One can then claim that the scarf-bundle resembles other scarf-bundles (at least, in contexts in which scarf-hood is raised to salience), whereas the mass-of-wool bundle fails to resemble scarf-bundles in this respect. In this way, one grounds modal differences in sortal differences, where those sortal differences are primitive.

This version of the bundle theory is an improvement on the one which takes modal properties to be primitive parts of bundles. It's plausible to the extent that it's plausible to take sortals as primitive features of objects. It's primitive that Chunky but not Woolly is a scarf. On this view, possession of sortal properties explains persistence conditions and other modal properties; but sortal possession itself has no explanation. Fixing the direction of explanation from sortal possession to persistence conditions sounds a plausible way to go: it's quite natural to say that Chunky wouldn't survive complete unravelling because it's a scarf. Nevertheless, I worry that this picture leaves too much in the nature of sortal properties 
unanalysed. What is it to be a scarf? What is the nature of the property being a scarf? On the current story, we can say what being a scarf entails: namely, having such-and-such persistence conditions and other modal properties. But beyond that, we can't say anything informative about what being a scarf is. That's a cost.

There is a second problem with McDaniel's and Paul's mereological bundle theories, quite apart from issues surrounding the grounding problem. (This issue will be crucial in $\$ 6$.) Their approaches accept what Barker and Jago (2015) call the possession thesis:

Possession thesis: A material object $x$ possesses property $F$ iff $F$ is a part of $x$ (qua bundle of properties).

Take the case of de re modal properties, understood as outlined above in terms of the object's counterparts. To be necessarily $F$ is to have no counterparts that are not $F$. Since being necessarily $F$ implies being $F$, each thing must be a counterpart of itself. So, for each bundle $x, x$ must include the property being a counterpart of $x$. That property's identity is partially fixed by $x$ 's identity. But, since $x$ is a bundle of properties, $x$ 's identity is also partially fixed by that very property. So we have a vicious circle of identity-fixing facts.

This kind of objection isn't specific to counterpart relations, of course. Any nonirreflexive relation will generate the problem. An instance $R x x$ must be analysed as $x$ possessing the property being $R$-related to $x$. That property's identity is partially fixed by $x$, and $x$ 's identity is partially fixed by that property. And indeed, the problem isn't even limited to reflexive instances $R x x$ of a relation $R$. The problem arises whenever there are cycles of relation-instances: $R x y$ and $R y x$, for example. In that case, the $x$-bundle includes the property being R-related to $y$ and the $y$-bundle includes the property being R-related to $x$. So $x$ 's identity is partially fixed by $y$ and $y$ 's is partially fixed by $x$.

This might be acceptable for those taking a holistic approach to material objects, where a plurality of objects may inter-depend on one another for their identity. (Elsewhere in this volume, Naomi Thompson discusses such a notion of inter-dependence.) The problem here is that bundle theories cannot accept this picture. A material object's identity must depend wholly on the properties thereby bundled. In the case just mentioned, $x$ 's identity depends in part of the property being $R$-related to $y$, but that property's identity depends in part upon $x$ 's identity (via the identities of $y$ and the property being $R$-related to $x$ ).

In summary, the benefits of McDaniel's and Paul's approaches are genuine, although limited. They do not give us an adequate solution to the grounding problem. I'll now show how a bundle theorist can improve matters and give a full solution to the problem.

\section{Essential Bundle Theory}

In this section, I want to argue for a new account of material objects, which furnishes us with a different response to the grounding problem. This approach incorporates McDaniel's and Paul's insights $\left(\mathbb{\$}_{5}\right)$, but avoids the problems raised 
above. The approach I favour, essential bundle theory (Barker and Jago 2015), is an independently-motivated account of material objects, which also furnishes us with a neat response to the grounding problem. I'll sketch the approach and the motivations I find in its favour in this section, and then show how it provides a suitable solution to the grounding problem in $\$ 7$.

Essential bundle theory is a bundle theory, but one which departs from traditional bundle theories in several respects. (I'll provide an overview of essential bundle theory here; see Barker and Jago 20 I 5 for more details.) As with McDaniel's (200I) and Paul's (2002; 2006) views, it adopts the mereological approach: bundles are mereological sums of properties. The parts of bundles are particular instances of properties, such as this bit of charge over here, not universals. Those property instances are individuated in terms of a property-type, such as charge, and a spatiotemporal location. One might think in terms of primitive tropes, or in terms of universals being instantiated by regions of spacetime. It doesn't matter which, so long as each property instance is associated both with a property type and with exactly one region of spacetime. (The region in question is the exact region throughout which the property in question is distributed, hence the uniqueness condition.) The properties in question are not restricted only to the fundamental ones: we allow properties such as being red.

Essential bundle theory takes a material object to be a suitably closed, consistent mereological sum of non-modal, non-sortal property instances, all of which share the same spatiotemporal region. I will unpack the closure clause below: roughly, it tells us that bundles containing is red will also contain is coloured, for example. The consistency clause plays a role if we have a conception of properties on which there are negative properties, such as not being red. No bundle contains both a property and its negation. We exclude modal and sortal properties from bundles, because we will analyse modal and sortal properties in terms of bundle-membership.

The region-sharing clause amounts to this: property instances $P_{1}, \ldots, P_{n}$ form a bundle only if there is some region $r$ such that each instance $P_{i}$ is associated (exactly) with $r$. This approach gives us a great deal of flexibility in what counts as a material object. We may allow the spatiotemporal regions in question to be spatially or temporally discontinuous, and in so doing allow for spatially discontinuous entities, like the Australian Capitol Territory. We may also allow temporally discontinuous entities, like the person who (due to strange facts about the continuity of her consciousness) exists only on Mondays, Wednesdays and Fridays (Braddon-Mitchell and West 2007).

Now let us unpack the closure clause. Say that a proposition $\langle A\rangle$ truthmaker entails a proposition $\langle B\rangle$ just in case any possible truthmaker for $\langle A\rangle$ is also a truthmaker for $\langle B\rangle$. (Details of the logic of truthmaker entailment can be found in Fine and Jago 20I 5.) Derivatively (and when ' $x$ ' is not free in either ' $F$ ' or ' $G$ '), say that $\langle F x\rangle$ truthmaker entails $\langle G x\rangle$ when, for any particular $a,\langle F a\rangle$ truthmaker entails $\langle G a\rangle$. Then a bundle $b$ of property instances is truthmaker closed just in case: $b$ contains an instance of $G$ whenever it contains an instance of $F$ and $\langle F x\rangle$ truthmaker entails $\langle G x\rangle$. The intuitive idea is that bundles containing, say, is red will also contain is coloured. If there are disjunctive properties, then bundles containing is red will also contain is red or blue. And if there are conjunctive 
properties, then bundles containing both is red and is large will also contain is red and large. But note that bundles are not required to be downwards-closed: a bundle may contain a determinable property, such as is red, without containing any determinate: not is scarlet, not is maroon, and so on. In short:

Material object: A material object is a consistent and truthmaker closed mereological sum of non-modal, non-sortal property instances, all of which are instanced throughout precisely the same spatiotemporal region.

There is one more important feature of essential bundle theory, which sets it apart from other bundle theories. Essential bundle theory rejects the possession thesis $(\mathbb{5})$, which analyses property-possession in terms of bundle-membership. In its place, essential bundle theory accepts:

NAture Thesis: Property bundles specify the nature or essence of the material object in question: object $x$ is essentially $F$ if and only if an $F$-instance is a part of the $x$-bundle.

A material object's nature is a bundle (a mereological sum) of properties, and an object is identified with its nature. That is the simple and basic idea which gives us both a good account of material objects and the best available response to the grounding problem.

Let me briefly sketch some of the motivations for and advantages of essential bundle theory. First, I'm motivated by the idea that metaphysics should not make large-scale assumptions about fundamental categories of being, which may turn out to be contradicted by fundamental physics. Although there clearly are material objects, it may well turn out that there are none at the fundamental level of reality. (Indeed, given contemporary physics in terms of quantum fields, I think it's quite likely that fundamental reality is devoid of material objects, as we know them.) That's a reason to favour theories on which objects are constructed from, or reducible to, some more fundamental category of being. Bundle theories answer to that description, in constructing material objects from properties.

That's a motivation for bundle theories in general but, as is well-known, traditional bundle theories face a host of problems, including Max Black's notorious two-sphere scenario in a completely symmetrical universe (Black I952). Essential bundle theory handles the worry by taking material objects to be bundles of property instances, rather than property types. Each such instance is associated with a spatiotemporal region. So, since the spheres in Black's scenario are spatially separated, sphere A and sphere B are sums of distinct pluralities of property instances. (This response presupposes a substantival view of spacetime. But I already assumed this approach, in saying that property instances are individuated in part by spatiotemporal region.)

Essential bundle theory also gives us a very natural notion of what material objects are, given prior acceptance of bundle theory in general. There's a very natural sense in which, when we ask that question, we are asking about the essence or nature of the objects in question. (Here, I am using 'nature' and 'essence' interchangeably.) Consider what Kit Fine says about the importance of the notion of essence: 
the concept [essence] may be used to characterize what the subject [metaphysics], or at least part of it, is about. For one of the central concerns of metaphysics is with the identity of things, with what they are. But the metaphysician is not interested in every property of the objects under consideration. ... what appears to distinguish the intended properties is that they are essential to their bearers. (Fine I994, I)

Here we find a link between 'the identity of things' and essences. This link is even more explicit in Locke, who defines real essence as 'the very being of any thing, whereby it is, what it is' (Locke I690/I997, bk.3, ch.3, \$I 5 ). So an essence or nature is what furnishes an object with an identity.

A bundle theory already assigns this identity-conferring role, however: a material object is identified with a bundle of properties. The identity of that bundle, and hence of the object, is given by the bundle's membership. Changing the bundle's membership results in a numerically distinct object. The obvious (and, as far as I can see, only) way to reconcile bundle theory with the Lockean notion of real essence is to treat bundle and essence as one and the same entity. This results in a three-way identification: a material object is a bundle of properties, which is that object's essence. Material objects are identical to their essences, qua bundles of properties. A material object is essentially $F$ just in case it has an instance of Fness as a part.

What does essential bundle theory say about accidental property possession? What is it to possess $F$ accidentally? To possess a property accidentally is to possess a property not in one's bundle. So we need to ask: what is the general story about property possession? (The full explanation appears in Barker and Jago 20I 5; I will give only a brief overview here.) Let us distinguish several kinds of material properties. First, we have those whose instances in region $r$ are grounded wholly by other property instances located in sub-regions of $r$. In this category, we find properties relating to mass, shape, temporal duration and so on. Call such properties region focused. A material object $o$ possesses a region-focused property $F$ iff $F$ is instanced throughout $o$ 's region. As a consequence, coincident objects share all their region focused properties.

Where $F$ is a sortal property, the story will be different. To say that something is a person, or an artwork, is to say something about what it is: we are talking about its essence. So we might say that an object $o$ possesses sortal $F$ iff $F$ is part of $o$ 's bundle. But we might also require that a sortal has certain preconditions: perhaps a person must be rational or have certain behavioural dispositions. The bundles we identify with objects are not downwards closed, however: they may contain a property $G$ without containing the grounds for $G$. So instead, we might analyse a sortal $G$ into further (non-sortal) properties $G_{1}, \ldots, G_{n}$ and say that an object $o$ is a $G$ iff each of $G_{1}, \ldots, G_{n}$ is part of $o$ 's bundle. Both approaches will entail that each spatiotemporally located person is coextensive with a distinct physical object that isn't a person.

We also have properties which are neither region-focused nor sortals, and which are grounded partly by what goes on outside of their region. Jeff Koons's Balloon Dog possesses the property being financially valuable, having sold for 
$\$ 58.4$ million in 2014. My balloon dog, by contrast, is worthless. Facts about Koons and his place in the art world, plus sociological and economic facts about the art community, are what make Koons's artefact an artwork, and what make it a valuable one. So being an artwork and being valuable are instanced in Koons's Balloon Dog's region (mostly) in virtue of artistic, social and economic properties being instanced externally to that region. Those external properties establish suitable preconditions for an artefact's being an artwork, or for an artwork's being financially valuable.

Crucially, these preconditions are preconditions for some object's possessing some property, insofar as that object falls under some sortal $G$. Let's call $G$ the key sortal for those preconditions. Being married's key sortal is being a person, for example. We can associate each property $F$ of this type with a key sortal $G$ : call such properties sortal focused. Now, consider some sortal focused property $F$ whose key sortal is $G$. Then material object $o$ possesses $F$ if and only if $o$ is a $G$ (as analysed above) and $F$ is instanced in o's region. The idea here is that the preconditions for something's being an artwork focus on an artefact, and that's why Koons's creation, but not the coextensive mass of rubber and air, possesses being an artwork.

\section{The Solution to the Grounding Problem}

Now it's time to return to the grounding problem. Essential bundle theory, I claim, provides a better solution than Bennett's, McDaniel's, and Paul's approaches. (Indeed, I think the approach is the best a pluralist can do.) My claim is that, when a material object possesses certain sortal properties and has certain persistence conditions, it is the object itself which grounds its possession of those properties. They are grounded in the very identity of the object in question. They are not primitive features of the object. We can explain why a given object possesses those very sortal properties and has those very persistence conditions. And we can do this without positing mysterious primitive modal properties. Here's how.

Given essential bundle theory, the grounding story of persistence conditions goes like this. An object is a bundle of property instances, and each such property is essential to the object in question. Chunky includes an instance being wearable (or some similar functional property which picks out the function performed by scarfs: being made of a material and fashioned into a form which allows us to put them on as clothing). Those properties ground a certain modal profile, which includes the object's persistence conditions. Chunky's essential wearability grounds its modal intolerance to being completely unwound, whereas nothing in its essence (and nothing in the essence of anything else, for that matter) rules out small-scale substitution of Chunky's matter.

In order to have a solution to the grounding problem, we needn't specify the exact manner in which an essence grounds certain persistence conditions. It is enough to show that substantial essences (of the kind used here) are suitable grounders for persistence conditions. The justification for that is the reasoning just sketched. If Chunky is essentially wearable, then any condition incompatible with 
being wearable is incompatible with Chunky. Although essence (as conceived here) is not inherently a modal notion, it of course has modal consequences. Something that's essentially $F$ could not have failed to be an $F$; and anything entailed by being an $F$ will be de re necessary of that thing. Similarly, anything that's excluded by being an $F$ will, of necessity, be lacked by the thing in question. Being wearable (for scarves, at least) excludes being completely unravelled. So, of necessity, Chunky cannot be completely unravelled without being destroyed. It is in this way that Chunky's essence grounds its persistence conditions.

We cannot account for an object's de re modal properties purely in terms of that object's essence, however. It's de re necessary, of Chunky, that $1+1=2$; but it's no part of Chunky's nature that $1+1=2$. Being essentially $F$ is sufficient, but not necessary, for being necessarily $F$. Nevertheless, it's plausible that the total distribution of de re necessary properties should depend on the total distribution of essential properties. Necessity flows from the essences of all things. More precisely, if some $x s$ are (together) essentially such that $a$ is $F$, then it is necessary that: $a$ is $F$ if the $x s$ all exist. Where the $x s$ are necessary existents, the antecedent is automatically satisfied, and it will be necessary that $a$ is $F$. But if there are no such $x s$, then $a$ is not necessarily $F$.

To illustrate the idea, suppose it's part of the essences of the numbers 1 and 2 that $1+1=2$; and suppose numbers are necessary existents. Then Chunky is such that, necessarily, $1+1=2$. Similarly, given that Chunky is essentially wearable, every entity is necessarily such that, if Chunky exists, then Chunky is wearable. (I haven't said anything here about the essences of abstract entities such as numbers. Perhaps they are bundles of properties instanced in abstract space. Perhaps that's why they are necessary existents. Or perhaps they have existence as part of their essence.)

Given this principle, it follows that Woolly will lack modal properties such as being necessarily wearable. For being wearable is not part of Woolly's essence, and no necessary existent has being such that Woolly is wearable as part of its essence. We can allow that there exist relational properties such as being such that Woolly is wearable; and we can allow that such properties are parts of bundles. So we might accept that some strange entity is essentially such that Woolly is wearable. But any such entity will be a contingent existent, and hence Woolly is not necessary wearable. (We might opt for a version of the theory which bans relational properties from being parts of bundles. But allowing for such properties is a promising way to account for the essentiality of origins, as when we say that I could not have had different parents.)

This principle entails a modal plenitude principle much like Bennett's (2004b) from $\mathbb{S}$. Any spatiotemporal region will instance many properties, and so there will exist many consistent, truthmaker closed bundles of properties in that region. This gives us many coincident material objects differing in their essences. Now suppose we can consult the essences of all other entities and discover which properties are contingent. Given some contingent property $F$ instanced in our region, no necessary existent's essence will say that any of those bundles are necessarily $F$. It follows that some but not all of those material objects are necessarily $F$. In short, for any modal profile one can come up with, given the 
properties instanced in our region, there will be some entity in the region that has that modal profile and another in the region that lacks it. So this approach supports (and indeed, explains) Bennett's modal plenitude principle. But note that it is not the plenitude principle itself that provides the solution to the grounding problem. Rather, the solution lies in the account of essence, that is, in the account of what material objects are.

The sortal grounding story is similar. We might identify the sortal being a scarf with a complex functional property $F$, insofar as it is possessed essentially. ( $F$ might be thought of as a conjunction of properties such as being wearable.) Something is a scarf insofar as $F$ enters into its nature: $x$ is a scarf just in case $F$ is a part of the $x$-bundle. That's why Chunky is a scarf. And although Woolly is wearable, warm, flexible, scarf-shaped and so on, it is not essentially so, and consequently it fails to be a scarf. Sortal differences are explained by (and grounded in) differences in essences.

One might worry that this form of explanation merely pushes the problem further back: essences explain sortals and persistence conditions, but what explains essences? An essence is merely a mereological sum of property instances. So the question, 'what grounds $x$ 's being essentially $F$ ?' is equivalent to the question, 'what grounds some $F$-instance's being a mereological part of $x$ ?' This is the point at which explanation does not (and cannot) go any further. It is a general feature of mereology that wholes are defined in terms of their parts: the identity of the whole depends on having each of those parts as parts. So, given the identity of some whole $y$, one cannot give an informative answer to 'why is $x$ a part of $y$ ?', other than by reiterating what $y$ is: it's simply the thing that has exactly such-and-such as its parts. So the explanation of why a material object has so-and-so essential properties reaches bedrock at an absolutely appropriate point.

In this way, essential bundle theory explains differences in sortals and persistence conditions between coincident objects in terms of the identities of those objects. It is not a primitivist account, precisely because it does not take possession of modal or sortal properties to be a primitive matter. Nevertheless, facts about a given entity's essence are not further reducible to other facts about that entity, on this picture. Those facts are just facts about its mereological parts, and hence about its identity as a whole composed of parts. No one should demand an informative answer to 'why is $x$ a part of $y$ ?'. The question simply doesn't arise; and so we have grounded modal and sortal properties - including modal and sortal differences between coincident objects - at an absolutely appropriate point.

\section{Conclusion}

The grounding problem bites hard for pluralists about coincident objects $(\mathbb{2})$. Neither conceptualist $\left(\mathbb{S}_{3}\right)$ nor primitivist $\left(\mathbb{S}_{4}\right)$ approaches provide an adequate solution. To solve the problem of how there can be coincident objects with distinct properties, one has to give a story of what those objects are. A bundle theory of material objects makes inroads into the problem $\left(\$_{5}\right)$, but takes us only so far. The 
crucial move, once we have adopted a bundle-theoretic solution to the problem, is to identify an object's essence with what the object in question is: a bundle of properties. When those properties are understood as property instances, this gives us essential bundle theory $(\mathbb{} 6)$. We then have a suitable notion of essence with which to ground modal and sortal differences between coincident objects $\left(\mathbb{S}_{7}\right)$. Essences themselves stand in no need of further explanation, on this view, for they are just mereological sums of property instances.

\section{References}

Barker, S. and Jago, M. (20I 5). Essential bundle theory. Unpublished manuscript.

Barker, S. and Jago, M. (20I4). Monism and material constitution, Pacific Philosophical Quarterly.

Bennett, K. (2004a). Global supervenience and dependence, Philosophy and Phenomenological Research 68(3): 50I-529.

Bennett, K. (2004b). Spatio-temporal coincidence and the grounding problem, Philosophical Studies I I 8(3): 339-37I.

Black, M. (I952). The identity of indiscernibles, Mind 6I(242): I 53-I64.

Braddon-Mitchell, D. and West, C. (2007). Temporal phase pluralism, Philosophy and Phenomenological Research 62(I): 59-83.

Burke, M. (1992). Copper statues and pieces of copper: a challenge to the standard account, Analysis 52(I): I2-I7.

Fine, K. (1994). Essence and modality: The second philosophical perspectives lecture, Philosophical perspectives 8: I-I6.

Fine, K. (2003). The non-identity of a material thing and its matter, Mind I I2(446): I95-234.

Fine, K. and Jago, M. (2015). Exact truthmaker logic. Unpublished manuscript.

Goswick, D. (2010). Bridging the modal gap, The Journal of Philosophy $\operatorname{IO} 7(8): 432-443$.

Heller, M. (I990). The ontology of physical objects: Four-dimensional hunks of matter, Cambridge University Press.

Johnston, M. (I992). Constitution is not identity, Mind IOI(40I): 89-IO6.

Korman, D. (20II). Ordinary objects, in E. N. Zalta (ed.), The Stanford Encyclopaedia of Philosophy, winter 20 I I edn.

Lewis, D. (I986). On the Plurality of Worlds, Blackwell, Oxford.

Locke, J. (1690/1997). An Essay Concerning Human Understanding, Penguin. 
McDaniel, K. (200I). Tropes and ordinary physical objects, Philosophical Studies IO4(3): 269-290.

Noonan, H. (I99I). Indeterminate identity, contingent identity and Abelardian predicates, The Philosophical Quarterly 4I(I63): I83-I93.

Paul, L. A. (2002). Logical parts, Nô̂s 36(4): 578-596.

Paul, L. A. (2006). Coincidence as overlap, Nô̂s 40: 623-659.

Robinson, D. (1985). Can amoebae divide without multiplying?, Australasian Journal of Philosophy 63(3): 299-3 I9.

Zimmerman, D. (1995). Theories of masses and problems of constitution, The philosophical review I04(I): 53-I IO. 